\title{
A nematode demographics assay in transgenic roots reveals no significant impacts of the $R$ h 1 locus LRR-Kinase on soybean cyst nematode resistance
}

\author{
Sara Melito', Adam L Heuberger'1, David Cook'1, Brian W Diers², Ann E MacGuidwin¹ and Andrew F Bent*1
}

\begin{abstract}
Background: Soybean cyst nematode (Heterodera glycines, SCN) is the most economically damaging pathogen of soybean (Glycine max) in the U.S. The Rhgl locus is repeatedly observed as the quantitative trait locus with the greatest impact on SCN resistance. The Glyma18g02680.1 gene at the Rhg 1 locus that encodes an apparent leucine-rich repeat transmembrane receptor-kinase (LRR-kinase) has been proposed to be the SCN resistance gene, but its function has not been confirmed. Generation of fertile transgenic soybean lines is difficult but methods have been published that test SCN resistance in transgenic roots generated with Agrobacterium rhizogenes.

Results: We report use of artificial microRNA (amiRNA) for gene silencing in soybean, refinements to transgenic root $\mathrm{SCN}$ resistance assays, and functional tests of the Rhg 1 locus LRR-kinase gene. A nematode demographics assay monitored infecting nematode populations for their progress through developmental stages two weeks after inoculation, as a metric for SCN resistance. Significant differences were observed between resistant and susceptible control genotypes. Introduction of the Rhg 1 locus LRR-kinase gene (genomic promoter/coding region/terminator; Peking/PI 437654-derived SCN-resistant source), into rhg 1-SCN-susceptible plant lines carrying the resistant-source Rhg $4^{+}$locus, provided no significant increases in SCN resistance. Use of amiRNA to reduce expression of the LRR-kinase gene from the Rhg 1 locus of Fayette (PI 88788 source of Rhg 1) also did not detectably alter resistance to SCN. However, silencing of the LRR-kinase gene did have impacts on root development.

Conclusion: The nematode demographics assay can expedite testing of transgenic roots for SCN resistance. amiRNAs and the PSM103 vector that drives interchangeable amiRNA constructs through a soybean polyubiqutin promoter (Gmubi), with an intron-GFP marker for detection of transgenic roots, may have widespread use in legume biology. Studies in which expression of the Rhgl locus LRR-kinase gene from different resistance sources was either reduced or complemented did not reveal significant impacts on SCN resistance.
\end{abstract}

\section{Background}

Soybean cyst nematode (SCN, Heterodera glycines) is an obligate, sedentary endoparasite that is consistently the most damaging pest of soybean in the U.S. [1]. Once SCN is present in a field it cannot feasibly be eradicated.

The SCN life cycle consists of five stages. After the first molt within the egg, SCN second stage juveniles (J2) hatch, move through the soil, penetrate roots and move

* Correspondence: afbent@wisc.edu

1 Department of Plant Pathology, University of Wisconsin - Madison, Madison, WI 53706 USA

Full list of author information is available at the end of the article toward the vascular cylinder [2,3]. Migratory juveniles select a host cell in the cortex, endodermis, or pericycle and induce host cell fusion as part of the formation of a permanent feeding site called a syncytium. At this point the nematode becomes sedentary and differentiates to the third (J3) and fourth (J4) juvenile stages and then matures to an adult female or male. Males undergo a metamorphosis to resume a vermiform shape at the J4 stage and migrate back out of the root to fertilize adult females. Following fertilization, the female produces eggs, most of which remain inside the body. After dying, the 
female body develops into a hardened cyst that encases the eggs. At $25^{\circ} \mathrm{C}$, some nematodes reach the adult stage 12 days after entering roots, and most become adults by 30 days post-infection [4].

Soybean cyst nematodes infect and grow in the roots of both resistant and susceptible cultivars [2,5]. Nematode growth and development depends on the successful establishment and maintenance of a syncytium, and impairment of the syncytium can give outcomes that range from reduced growth and reproduction to death. The available SCN resistance in soybean is partial, and can be observed as a reduced number of females that develop compared to the number that develop on similarly inoculated susceptible cultivar controls [6]. In intact soybean plants, resistance is often expressed as the female index (FI): the number of fully developed females (cysts) on the tested soybean genotype divided by the number of females on a susceptible standard [2,7]. Soybean cultivars are generally classified as strongly resistant to $\mathrm{SCN}$ if the FI is less than 10\%; partial levels of resistance can also be useful [8].

The SCN resistance in current commercially grown soybeans is derived from a very small number of sources [9]. These sources include 'Peking' (PI 548402), PI 88788 and PI 437654, which have each been shown to carry resistance loci effective against multiple nematode races $[10,11]$. Inheritance of resistance to SCN was first reported in the 'Peking' plant introduction, and three genes for resistance (rhg1-rhg3) were assigned and initially classified as recessive [12]. Of the resistance sources, PI 88788 has been the most widely used in breeding programs. More than $95 \%$ of the SCN resistant cultivars available for planting in Illinois during 2009 received their resistance from this PI [13].

The Rhg1 locus has been shown to have the greatest impact on SCN development in several resistance sources including Peking, PI 88788, PI 437654, PI 209332 and PI 90763. This locus provides resistance to many common SCN populations such as $\mathrm{Hg}$ type 0 (race 3) [10]. Multiple research groups have mapped the Rhg1 locus to a subtelomeric region on chromosome $18[11,14,15]$, to a location approximately 0.4 centimorgans $(\mathrm{cM})$ from the simple sequence repeat (SSR) marker Satt309 [16] (chromosome 18 was formerly known as linkage group G; http://www.phytozome.net/[17]). Although originally reported as a recessive locus, "rhg1" has more recently been characterized as exhibiting incomplete dominance. Soybean lines heterozygous for resistant and susceptible alleles at the Rhg1 locus often allow SCN cyst formation at a rate intermediate between that of plants genotyped with Satt309 as homozygous resistant or homozygous susceptible at the Rhg1 locus [18-20](Kim et al. submitted; incomplete dominance also has been observed in unpublished work with the Ina $\times$ E98076 material used in this study). A second QTL (Rhg4) has been identified as being necessary for full resistance to some $\mathrm{SCN}$ populations in Peking and in PI 437654, but not PI 88788 or PI $209332[7,9]$. Rhg4 exhibits dominant gene action, and in Peking-derived material the relevant alleles of both $R h g 1$ and Rhg4 are necessary to exhibit the full resistance phenotype. Other loci that make smaller and/or more racespecific contributions to $\mathrm{SCN}$ resistance have also been identified throughout the soybean genome, but often a given locus was identified in only one study [10,21-25].

Cytological studies suggest that Peking-type resistance displays host cell necrosis and cell wall appositions not seen in PI 88788 type resistances in response to $\mathrm{SCN} \mathrm{Hg}$ type $0[26,27]$. The Peking and PI 88788 Rhg1 sources also exhibit distinct differential behaviors in their strength of resistance against particular SCN test populations, suggesting at least partially different mechanisms in the SCN resistance controlled by different $R h g 1$ alleles $[28,29]$.

Two groups first filed applications with the U.S. Patent Office in 2000 identifying apparent leucine-rich repeat transmembrane receptor-kinase (LRR-kinase) genes currently annotated as Glyma18g02680.1 and Glyma08g11350.1 http://www.phytozome.net/[17] as the likely SCN resistance genes at both $r h g 1$ and $R h g 4[18,30]$, see also [19,31]. Sequences supporting the claims were released to Genbank between 2000 and 2005. The basis for these claims was the presence of these genes at the $R h g 1$ and $R h g 4$ loci, their similarity to the known rice bacterial blight resistance gene $\mathrm{Xa21}$, and the presence of derived amino acid sequence differences between the alleles from resistant and susceptible plant genotypes. However, a decade later, no functional evidence for a role of these LRR-kinase genes in SCN resistance has been reported in a peer-reviewed forum. There are numerous reasons why identification of the Rhg1 gene that confers $\mathrm{SCN}$ resistance is a high priority, including the extreme economic significance of SCN for yield loss, the major reliance on the Rhg1 locus in commercial soybean breeding, the detection of SCN populations that overcome currently available $R h g 1$-mediated resistance, the potential to respond to these challenges with engineered improvements in Rhgl, and basic scientific interest in the nature of plant resistance to $\mathrm{SCN}$.

An experimentally tractable transgenic assay system is a crucial component for the identification, study and manipulation of genes controlling SCN resistance as well as many other soybean traits. Generation of transgenic fertile soybean lines is still a difficult and expensive process that requires close to a year to obtain transgenic seed lines. Agrobacterium rhizogenes has been used by many researchers as a transgene delivery system to study legume root biology, both in soybean and Medicago truncatula [32-36]. Transgenic roots generated using $A$. rhizogenes retain the $\mathrm{SCN}$ resistance phenotypes of the 
parental soybean genotypes, and have been used to test genes that may impart resistance $[37,38]$.

Function is often attributed to specific genes by the methods of gene mutation/positional cloning, phenotypic complementation via transformation with a cloned fulllength gene, and/or by gene silencing. Experimental silencing of plant genes has generally been elicited using hairpin RNA-forming inverted repeat DNA constructs or by virus-induced gene silencing [39-42]. All silencing approaches are prone to incomplete penetrance (partial silencing, often for unpredictable reasons), but have nevertheless been useful for assigning function to specific genes, and for engineering useful traits. These gene silencing techniques have been used effectively in soybean and other legumes [43-49]. With the more recent discovery of endogenous microRNAs as a major mode of gene regulation in many eukaryotes, artificial microRNA (amiRNA) methods have been developed for investigatorinitiated silencing of target genes [50-52]. Potential advantages of amiRNAs may include better penetrance, absence of undesired phenotypes associated with VIGS virus infections, and the capacity to limit off-target silencing of related sequences by elicitation with constructs specific for very short (19-24 bp) target sequences. However, use of amiRNA technology with soybean, M. truncatula, Phaseolus or other legumes has not been reported.

For the present study we refined assays that test SCN resistance in transgenic roots generated with $A$. rhizogenes. A nematode demographic assay was developed that discriminates resistant and susceptible responses by monitoring the infecting population for progression through nematode life stages. We also developed an amiRNA vector system for induction of gene silencing in legume roots using $A$. rhizogenes assay systems. We used these tools to investigate the impact on $\mathrm{SCN}$ resistance of the LRR-kinase gene from the Rhg1 genomic region (the candidate SCN resistance gene). Our experiments expressing the LRR-kinase from a resistant (Peking/PI 437654-source) Rhg1 locus in susceptible test lines, with or without the resistant allele at Rhg4, and silencing the LRR-kinase (PI 88788 source) in resistant lines, provided no evidence for a contribution of this gene to $\mathrm{SCN}$ resistance.

\section{Results}

\section{Scoring resistance using a hairy root/nematode} demographics assay

In soybean, Medicago truncatula and other plants for which stable transformation is difficult, transgenic "hairy roots" generated through A. rhizogenes-mediated transformation are often used to investigate gene function. A number of groups have previously shown that the resistance response to $\mathrm{SCN}$ in A. rhizogenes-derived roots correlates well with the SCN resistance phenotypes of intact soybean plants $[37,38]$. Cyst formation is typically counted after 4 weeks but because the root tissues used often exhibit significantly reduced vigor 3-4 weeks into such assays, and to expedite and possibly improve resistance scoring, we investigated the scoring of resistance phenotypes at an earlier time point. Host resistance to SCN is often manifested as arrested development at specific life stages [38,53], so we developed a "nematode demographics assay" in which SCN-infested transgenic root sections were stained with acid fuchsin approximately 2 weeks after inoculation with nematodes. Using a stereo dissecting microscope, the number of nematodes at each growth stage (J2, J3, or J4 + adult) was recorded for each root segment (Figure 1A,B,C). Data are expressed as a ratio: the number of nematodes within a root segment with an appearance resembling the J4+ adult, or J3 + J4 + adult, growth stage divided by the total number of nematodes $(\mathrm{J} 2+\mathrm{J} 3+\mathrm{J} 4+$ adult $)$ within the root segment. Relative $\mathrm{SCN}$ resistance or susceptibility is determined by comparison to the demographic data for known $\mathrm{SCN}$-resistant or SCN-susceptible host genotypes tested within the same experiment. The results of two such assays are shown in Figure 1D and 1E. In these and other experiments (below and data not shown) there was a reproducible significant difference between the SCN resistance phenotypes determined for known SCN-susceptible and $\mathrm{SCN}$-resistant control genotypes.

\section{No elevation of SCN resistance observed in susceptible genotypes transformed with the Rhg 1 locus LRR-kinase gene from resistant germplasm}

The Rhg1 locus of soybean has been shown in numerous studies to be the QTL with the greatest phenotypic impact on SCN resistance, and previous patents and other reports have indicated but not demonstrated that the Glyma18g02680.1 gene at the Rhg1 locus that encodes an apparent leucine-rich repeat transmembrane receptor kinase (LRR-K) is the source of this SCN resistance. We isolated this LRR-K gene from the Rhg1 locus using genomic DNA from the soybean cultivar Ina that we confirmed to exhibit SCN resistance in a standard whole plant/cyst formation assay immediately prior to its use in DNA isolation. Ina was used because of available progeny lines that are described below; Ina has Peking, PI 437654 and PI 88788 in its pedigree but carries an LRR-K at the Rhg1 locus that is identical in sequence to the Peking allele and also similar to the PI437654 allele. Multiple independent PCR products were isolated and sequenced, and the sequences were compared to each other and to the Peking sequence published in [30] to identify the best clone. An Agrobacterium-compatible binary vector pGWB1::erGFP7INT carrying a screenable intron-GFP marker was constructed to transform soybean with can- 

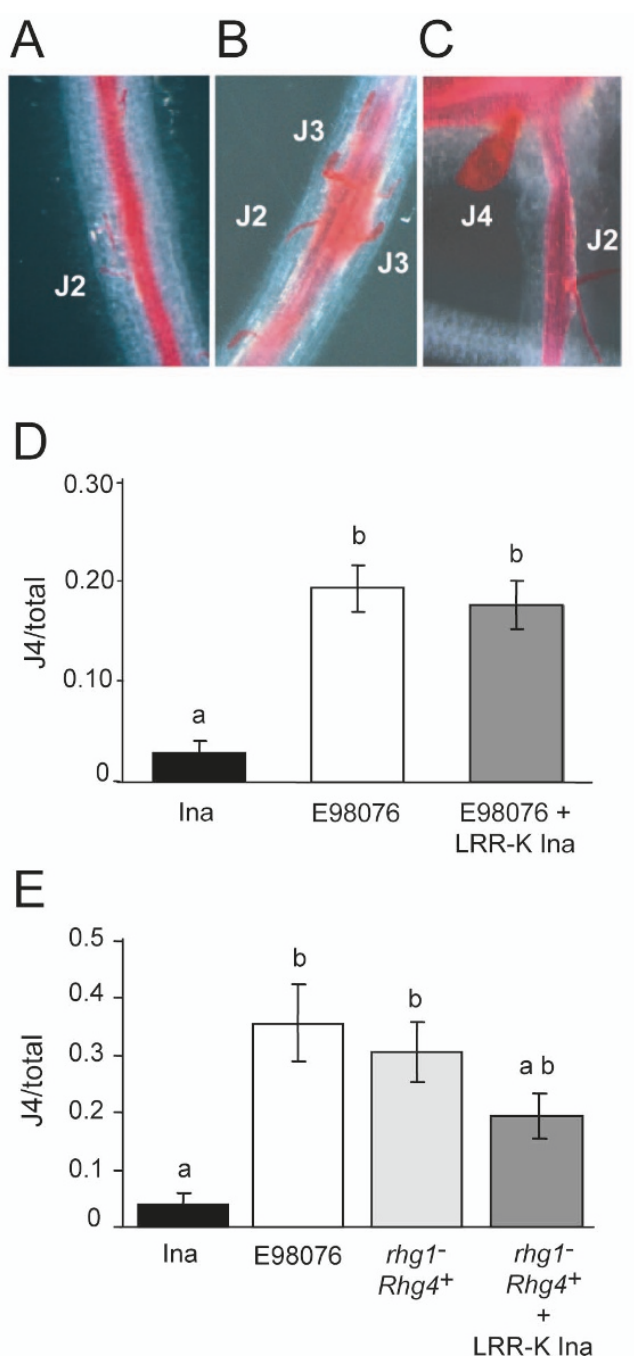

Figure 1 Nematode demographics assay for SCN resistance in roots transformed with a full-length $R$ h 1 1-locus LRR-Kinase gene. A, B, C, Representative examples of SCN developmental stages on transgenic soybean hairy roots 15 days after infection; cleared root sections were stained with acid fuchsin, which stains nematodes as well as root vascular bundles. A, Early parasitic second-stage juveniles (J2). B, Late parasitic J2s and early J3s. C, J4 or adult female. D, Ratio of total infecting nematode population that developed to $\mathrm{J} 4 \mathrm{O}$ or adult female stage two weeks after inoculation onto A. rhizogenens-transformed roots of Ina, E98076 (both transformed with empty vector), or E98076 + LRR-K Ina (transformed with the Glyma18g02680.1 Rhg1-locus LRRKinase promoter/gene/terminator). Mean \pm std error of mean; data combined from two independent experiments; bars with the same letter above are not significantly different (ANOVA, Tukey pairwise comparison, $\mathrm{p}<0.001$ ). E, Similar to D, except that "rhg 1-Rhg4+ are putative rhg 1-Irhg 1-; Rhg 4+/Rhg4+ progeny lines from Ina $\times$ E98076 that were genotyped as carrying the E98076 (susceptible) allele of a marker linked to Rhg 1 and the Ina (resistant) allele of a marker linked to Rhg4. All the lines were transformed with empty vector except "rhg 1- Rhg $4^{+}$ + LRR-K Ina" was transformed with Rhg 1-locus LRR-kinase gene (including native promoter and terminator). Mean \pm std error of mean are from two independent experiments; bars with the same letter above are not significantly different (ANOVA, Tukey pairwise comparison, $p<$ 0.05) didate $\mathrm{SCN}$ resistance genes in full-gene complementation experiments. An insert of $6.9 \mathrm{~kb}$ was added to pGWB1::erGFP7INT and included approximately $2 \mathrm{~kb}$ of genomic upstream DNA, the predicted 2757 bp LRR-K coding region + intron, and approximately 800 bp of downstream DNA. SCN-susceptible E98076 was then transformed with this construct to test the impact of this LRR-K allele on SCN development. Using the nematode demographics assay described above, roots from soybean line E98076 transformed with the Rhg1 locus LRR-K did not display increased resistance to SCN; nematode development progressed similarly to what was observed on E98076 susceptible control roots transformed with the empty pGWB1::erGFP7INT vector (Figure 1D). E98076 transformed with either an empty plasmid vector or with the Rhg1 locus LRR-K were, however, both significantly more susceptible to $\mathrm{SCN}$ than the resistant line Ina ( $\mathrm{p}$ 0.001).

The Rhg4 locus in Peking and PI 437654 also contributes to the full SCN resistance phenotype [10]. SCN-susceptible soybean genotypes with endogenous SCNsusceptible alleles at both Rhg1 and Rhg4, which are then transformed with a resistant allele only of Rhgl, might not display a resistant phenotype. To further test the impact of the Rhg1 locus LRR-K gene on SCN development, rhg1- lines carrying the SCN-resistant Peking Rhg4 locus were tested by complementation. Microsatellite markers linked to Rhg1 and Rhg4 were used to identify Ina $\times$ E98076 progeny lines with a $(-/-,+/+)$ genotype $\left(r h g 1_{\mathrm{E} 98076} / r h g 1_{\mathrm{E} 98076}, R h g 4_{\text {Ina }} / R h g 4_{\text {Ina }}\right)$. These lines were transformed with the cloned Ina Rhg1-locus LRR-K gene and assayed for SCN development. In the combined results from two independent experiments, no significant change in the resistance to SCN was detected after transformation of these genotypes with the Ina (Peking)derived Rhg1 locus LRR-K gene (Figure 1E). The two rhg1- lines transformed with an empty vector were significantly more susceptible to SCN than resistant Ina ( $\mathrm{p}<$ 0.01 ), while the $r h g 1_{\mathrm{E} 98076} / r h g 1_{\mathrm{E} 98076}, R h g 4_{\text {Ina }} / R h g 4_{\text {Ina }}$ genotype transformed with the Rhg1 locus LRR-K gene was not significantly more resistant than the same genotype transformed with empty vector. The mean resistance of roots transformed with the Ina LRR-K gene may have been slightly greater but not to a significant extent, in contrast to the statistically significant difference between the Ina and E98076 control lines. When the nematode demographics data for these same experiments were expressed as $[(\mathrm{J} 3+\mathrm{J} 4) /$ total $]$, the results for $r h g 1_{\mathrm{E} 98076} /$ $r h g 1_{\mathrm{E} 98076}, R h g 4_{\text {Ina }} / R h g 4_{\text {Ina }}$ genotypes transformed with empty vector or vector $+R h g 1$ locus LRR-K gene were even more similar (mean \pm std error $0.59 \pm 0.09$ for empty vector and $0.49 \pm 0.09$ for LRR-K Ina; $\mathrm{P}=0.85$ for ANOVA Tukey simultaneous tests). 


\section{Construction of an amiRNA gene silencing vector}

We sought to use gene silencing as an independent means to test for contributions of the Rhg1 locus LRR-kinase gene toward SCN resistance. To facilitate this work, we constructed a new vector for gene silencing in transgenic soybean roots. The binary vector pSM103 (pCAMBIA1300::35SP-erGFP7INT-NOS, Gmubi promoter, mi319RNAa) was designed to meet the following requirements: 1) efficient cloning of artificial microRNAs, 2) constitutive strong amiRNA expression in legume roots as well as other tissues [54], 3) reliable identification of transgenic roots by GFP screening using an intron-containing GFP that is not expressed in bacteria, 4) competence for transferring inserted DNA into plant genomes via Agrobacterium, and 5) high transformation efficiency. The steps taken to develop the vector are shown in Figure 2, as the intermediate constructs may also be of use and are available upon request. To initially confirm GFP7 expression in planta, pSM101 and pSM103 were infiltrated into $N$. bentamiana leaves using A. tumefaciens GV3101. Positive and negative controls (pGWB1::35SP-erGFP7INT-NOS, and A. tumefaciens GV3101 without any vector) did or did not produce green fluorescence respectively, as expected (Figure $3 \mathrm{~A}$ and $3 \mathrm{~B}$ ). erGFP7INT expression was phenotypically detected with use of vectors pSM101 and pSM103 (Figure 3C and 3D).

\section{Silencing of the Rhg 1 locus LRR-Kinase in transgenic roots}

For silencing experiments, the Rhg1 locus from the more widely used PI 88788 source of Rhg1 was tested using the soybean cultivar Fayette. Cotyledons of Fayette were transformed with A. rhizogenes containing pSM103 derivatives carrying one of two different amiRNAs that each were designed to specifically target the Gm18 Rhg1 locus LRR-K gene. To determine the effectiveness of the two amiRNAs, RNA was extracted from three independent transgenic hairy roots for each construct. Semiquantitative RT-PCR was performed in each of two independent biological replicate experiments as shown in Figure 4A. The semi-quantitative RT-PCR was also performed using Fayette GFP-negative hairy roots to determine the basal expression level of the Rhg1 locus LRR-kinase gene, and using Fayette GFP-positive roots to verify that unmodified pSM103 does not interfere with expression of the Rhg1 locus LRR-kinase gene. No significant differences were found between the two Fayette controls (Figure 4A and 4B). ANOVA was utilized to evaluate differences in expression of the Rhgl locus LRR-K gene. As shown in Figure 4A and 4B, at 35 cycles only the "amiRNA LRR-K I" construct was able to substantially reduce the expression level (mRNA abundance) of the Rhg1 locus LRR-kinase gene in transgenic roots (ANOVA $\mathrm{p}<0.05)$. No statistical difference was found for the amiRNA LRR-K II, but a trend of partial down regulation was observed (Figure 4B). The actin control did not show a significant difference among the samples.

\section{Impacts on Transformation Efficiency and Root Development}

Transformation efficiency was evaluated 3 weeks after $A$. rhizogenes application, with GFP used as a visual marker for successful transformation. Transformation frequency was calculated as the number of cotyledons with at least one transgenic hairy root divided by the total number of inoculated cotyledons. Fayette and Williams 82 transformed with pSM101, pSM103 and pGWB1::35SPerGFP7INT showed transformation efficiencies ranging from $43.33 \%$ to $50 \%$. No significant difference in transformation efficiency was observed between the two genotypes transformed with the different control vectors (Figure 5B). However, when Fayette cotyledons were transformed with amiRNA GmLRR-K I and amiRNA GmLRR-K II, decreased transformation efficiency was observed. Cotyledons transformed with the two LRRkinase amiRNA constructs developed hairy roots roughly two weeks later, and had lower transformation efficiencies than the controls. In particular, the amiRNA GmLRR-K I gave the lowest transformation efficiency $(8.37 \%)$ and the resulting roots grew more slowly (Figure $5 \mathrm{~A}$ and $5 \mathrm{~B}$ ). Based on two independent transformation experiments using 20 cotyledons of each genotype, a Chisquare test revealed no significant different between Williams and Fayette controls for root transformation efficiency $\left(\mathrm{X}^{2} \mathrm{P}=0.518\right)$, while a significant difference was observed for amiRNAGmLRR-K I $\left(\mathrm{x}^{2} \mathrm{P}=3.56 \mathrm{e}-10\right)$ and amiRNA GmLRR-K II ( $\left.\mathrm{X}^{2} \mathrm{P}=1.156 \mathrm{e}-4\right)$ relative to the expected rate established from Fayette controls.

To evaluate potential artifactual impacts of the amiRNA vector in plants lacking the target gene, a transformation experiment was performed using Medicago truncatula. The Fayette TC204550 sequence has only $81 \%$ identity with $M$. truncatula Chromosome 5 clone mth2-155g22 (CU302335). M. truncatula seeds were transformed with $A$. rhizogenes to deliver the same silencing constructs tested in soybean. Three plates, each with 12 germinated plants, were used for each construct. Three weeks after the treatment, no difference in root development was observed between $M$. trucatula seedlings transformed with the two amiRNA GmLRR-K constructs in comparison to the unmodified pSM103 vector. The transformation efficiencies were not substantially different, ranging from $10 \%$ to $30 \%$ amongst the plates (data not shown). These results indicate the amiRNAs designed to silence the soybean Rhg1 locus LRR-kinase gene have a root development impact specifically in soybeans. 

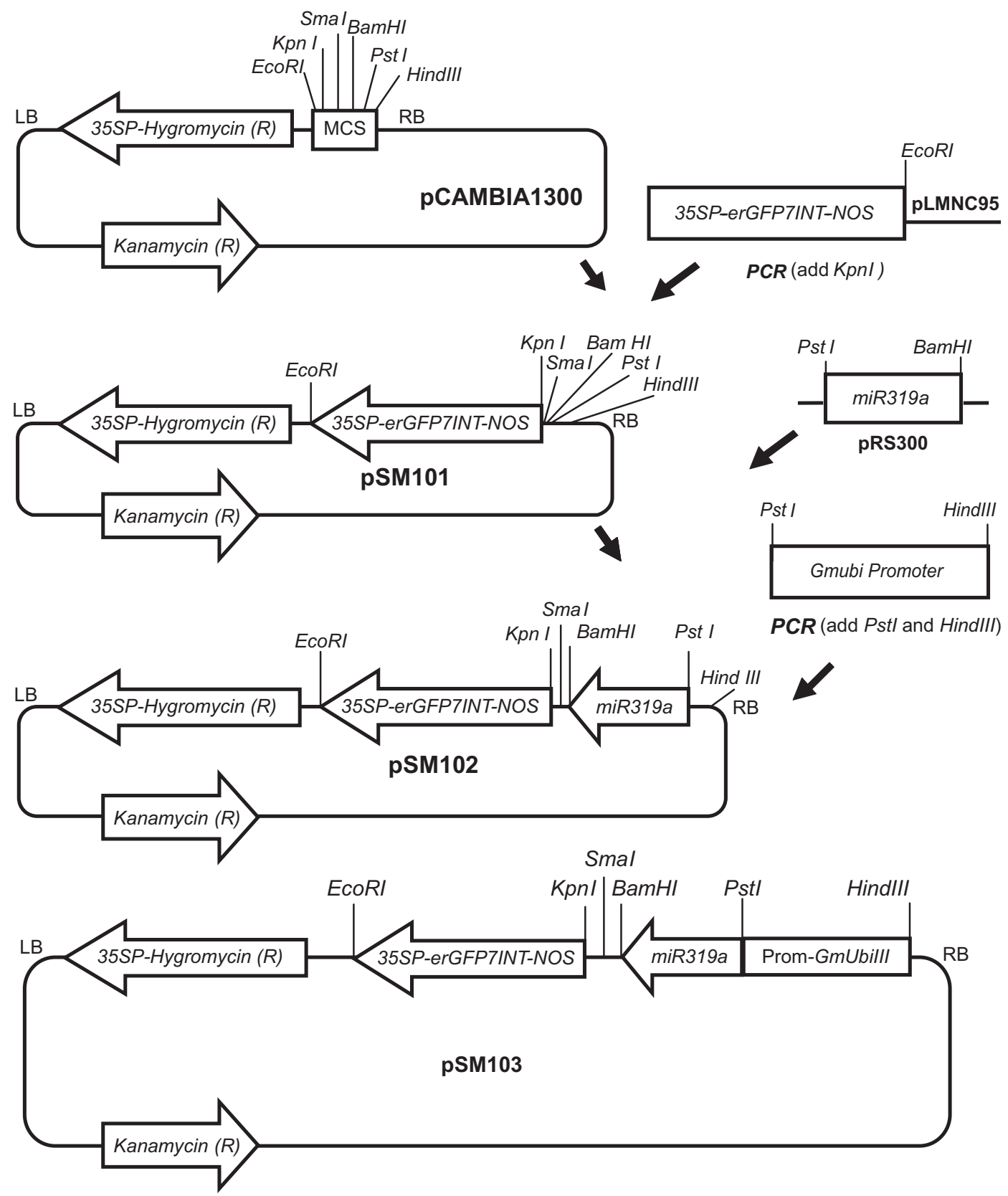

Figure 2 Construction of pSM103, a plasmid for amiRNA-mediate gene silencing in legume roots. pSM101 is an intron-GFP7 Agrobacteriumcompatible binary plasmid for plant transformation, derived from pCAMBIA1300 by addition between T-DNA borders of a 35S promoter-erGFP7INTNOS terminator (Mankin et al. 2001). pSM102 is pSM101 with a promoterless Arabidopsis miRNA miR319a gene. pSM103 is pSM102 with the miR319a driven by a promoter from the soybean ubiquitin-3 gene for strong expression in legume roots. After opening with Pstl and BamHI to remove the miR319a, pSM103 can receive user-designed amiRNA gene silencing constructs from the widely used plasmid pRS300 (http://wmd3.weigelworld.org/ ; Schwab et al 2006), or other constructs.

\section{No Significant Impact on SCN Resistance after Partial Silencing of the Rhg 1 locus LRR-kinase}

Healthy transgenic GFP-positive roots expressing amiRNA constructs that target the Rhg1 locus LRR-K gene (or empty vector controls) were sub-cultured by propagating the young growing tips $(2-3 \mathrm{~cm})$, and were infected with $\sim 250$ sterile J2 SCN for each root. The nematode demographics assay was then used to detect relative SCN resistance. The experiment was repeated with three independent biological replicates each using 4-10 


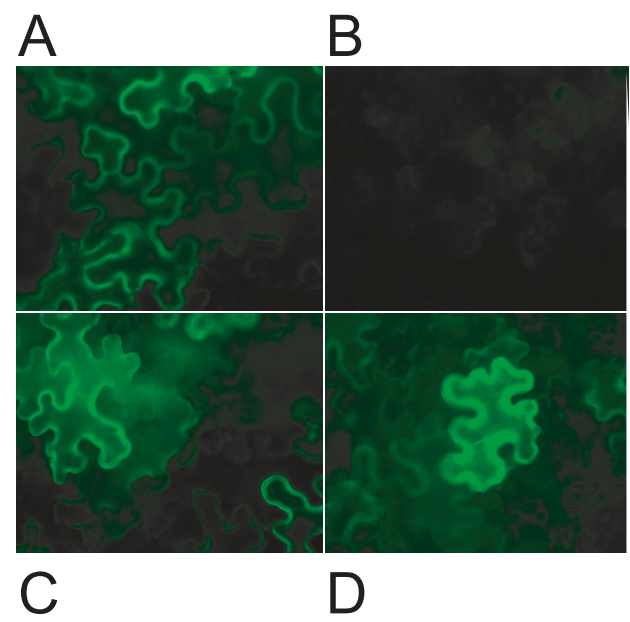

Figure 3 Transient expression of pSM101 and pSM103 in Nicotiana benthamiana leaves. A, B, C, The new binary vectors pSM101 and PSM103 were tested for GFP7 expression in Nicotiana benthamiana leaves. Bacterial suspensions were infiltrated through the abaxial surface of the leaf and GFP7 expression was monitored three days later by fluorescence microscopy. Leaves were infiltrated with: $\mathbf{A}$, positive control A. tumefaciens GV3101 pGWB1::35S-erGFP7INT-NOS; B, negative control untransformed $A$. tumefaciens GV3101; C\&D, A. tumefaciens GV3101 pSM101 (C) or pSM103 (D) that carry intron GFP7 constructs.

separate transgenic hairy roots of each treatment-construct. Two weeks after nematode inoculation, all nematode stages (except eggs) were observed in the transgenic roots tested, and the number of nematodes at each stage was recorded. Roots carrying five or fewer nematodes were excluded from further analysis. As expected, Fayette control roots allowed significantly fewer nematodes to molt and progress to an apparent J3 or J4/adult female stage within 14 days relative to Williams 82 control roots (Figure 6; $\mathrm{p}=0.007$ ). In the key comparison to test if silencing of the Rhg1 locus LRR-kinase gene altered resistance to SCN, no statistical difference in nematode development was observed between Fayette and Fayette carrying amiRNA GmLRR-K I or amiRNA Gm-K II (Figure 6).

\section{Discussion}

As one part of this study, we report use of amiRNA technology to knock down expression of an endogenous gene in soybean. Like RNAi (hairpin RNA or VIGS-mediated silencing), miRNAs and amiRNAs in plants reduce gene expression primarily by eliciting cleavage of homologous RNA transcripts. The primary benefit of adopting amiRNA technology is specificity [50-52]. Longer hairpin RNA gene silencing constructs (often 100-800 bp) are cleaved into multiple subfragments that, with the known tolerance for mismatches within the RNA-induced silencing complex, can cause unintended silencing of

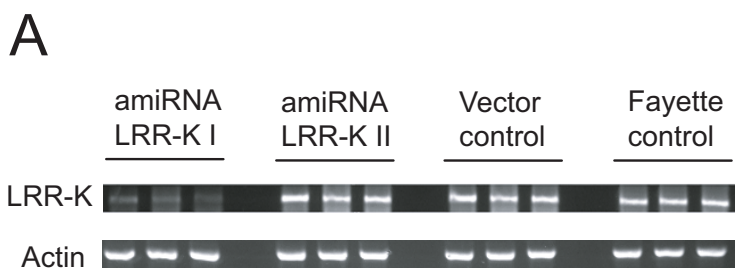

B

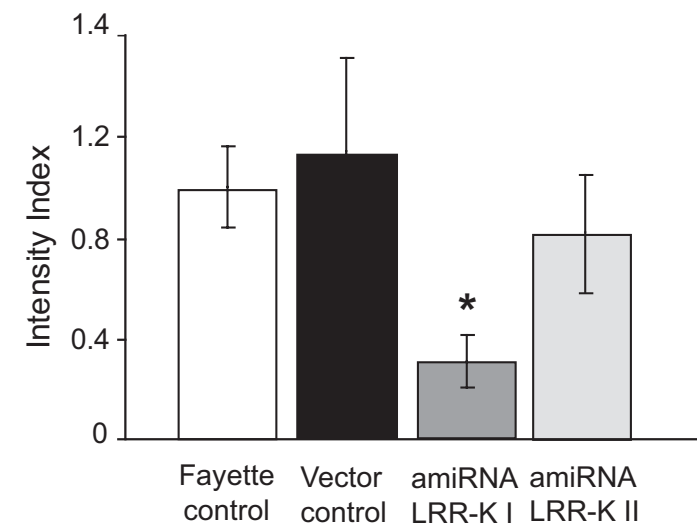

Figure 4 amiRNA-mediated silencing of expression of the Rhg 1locus LRR-kinase gene. A, Semi-quantitative RT-PCR to monitor expression level of the Rhg1-locus LRR-kinase gene Glyma18g02680.1/ TC204550 (LRR-K) in Fayette transgenic roots generated using pSM103-derived plasmids expressing amiRNA GmLRR-K I or amiRNA GmLRR-K II, or GFP7-positive Fayette transgenic roots generated using the negative control vector pSM103 (vector control), or GFP-negative Fayette hairy roots. Actin expression was monitored in parallel from the same samples as a control. Results from three independent roots are shown for each construct; gels were stained with ethidium bromide. Similar results were observed in a second experiment using independently derived roots. B, Relative band intensity of semiquantitative RT-PCR products. Data from the experiment shown in part $A$ and from a similar but independent transformation experiment are shown. Band intensities were normalized to the mean value for the three Fayette control roots from the same experiment. Mean \pm std error of mean are shown; statistical analysis was performed on the normalized data. Roots expressing amiRNA GmLRR-K I exhibited a significantly reduced mRNA abundance for the Rhg1-locus LRR-kinase gene, as indicated with the * (ANOVA; Tukey comparison of means; $p$ $=0.0023$ ).

non-target genes. This can readily remain undetected by the investigator. The target recognition portion of miRNAs and amiRNAs are very short and are strand specific, and plant miRNA-mediated silencing is more sequencespecific than animal miRNA-mediated silencing, all of which greatly reduces the potential for unintended offtarget effects on other genes. Based on known target selectivity behaviors (see for example http:// wmd3.weigelworld.org/ and [50], the amiRNA can be 

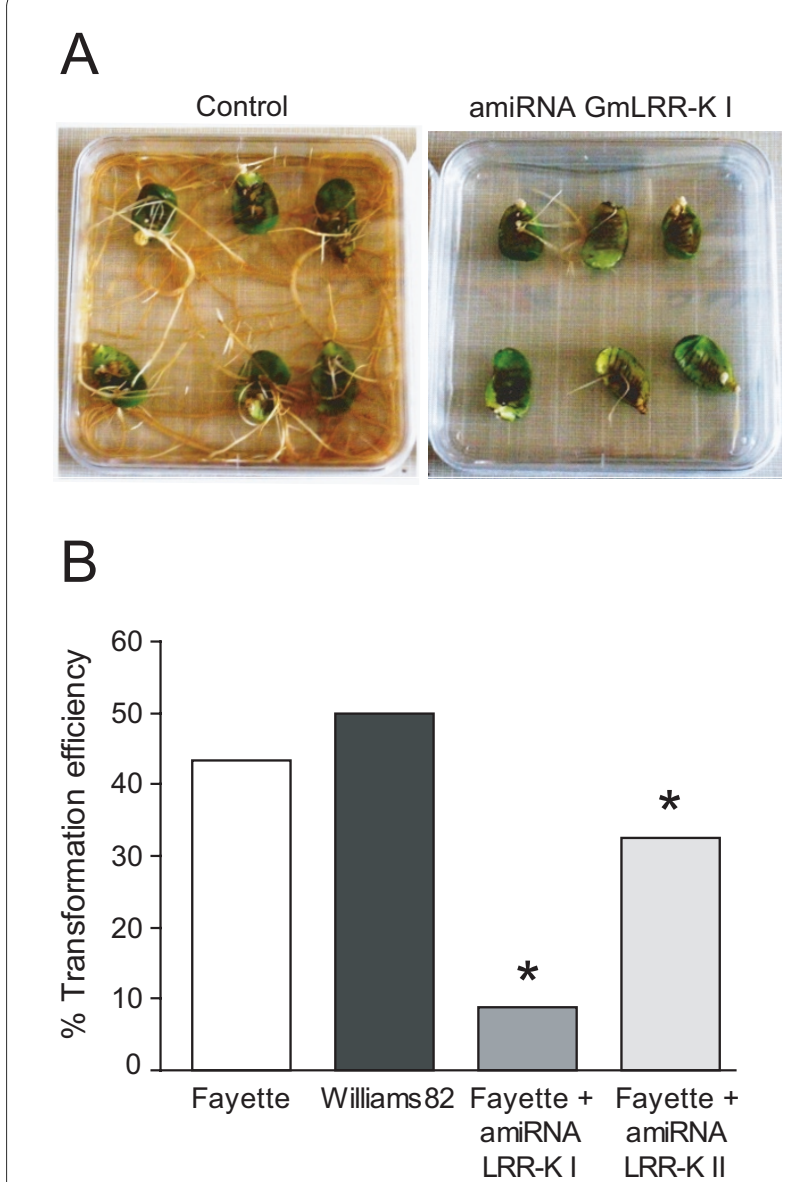

Figure 5 Root production by soybean cotyledons transformed using $A$. rhizogenes carrying amiRNA silencing constructs. A, Fayette cotyledons three weeks after treatment with A. rhizogenes pSM103 (control, plasmid carries A. thailiana miRNA319a lacking any known. soybean target), or with A. rhizogenes PSM103 derivative carrying amiRNA GmLRR-K I. Representative explants are shown. B, Transformation efficiency reduction when $A$. rhizogenes deliver amiRNAs targeting the Rhg1-locus LRR-kinase gene. Efficiency is the \% of treated cotyledons that produced at least one GFP7-positive root segment; * indicates significant difference from Fayette control ( $X^{2}$-test, see text). Cotyledons transformed with pSM103 derivates carrying amiRNA GmLRR-K I developed roots approximately two weeks later than those transformed with the control pSM103 vector, and developed fewer roots per cotyledon. This effect was also present, but less dramatic in the cotyledons that received the amiRNA GmLRR-K II.

designed to be gene specific - even targeting specific splice forms - but like other gene silencing methods, amiRNAs can alternatively be designed to silence multiple similar genes if an appropriate shared target sequence is used.

We constructed the vector pSM103 to address three goals: ready acceptance of newly generated amiRNA constructs into an Agrobacterium plant transformation vector, strong expression of the amiRNA in multiple tissues in soybean, and presence of an intron-disrupted GFP to

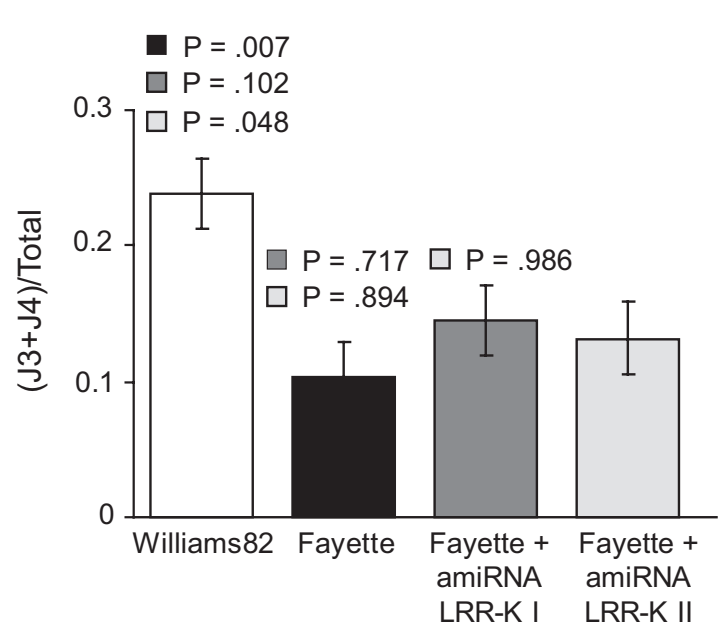

Figure 6 Nematode demographic assay for SCN resistance in roots transformed with amiRNA silencing the Rhg1-locus LRR-kinase gene. Ratio of total infecting nematode population that gained appearance of $\mathrm{J} 3$ and J4/adult female stages two weeks after inoculation onto A. rhizogenes-transformed roots. Williams 82 (susceptible) and Fayette (resistant) soybean tissue (left two bars) were transformed using A. rhizogenes carrying the pSM103 negative control plasmid; Fayette + amiRNA received the designated amiRNAs that target the Rhg 1 locus LRR-kinase gene (amiRNA LRR-K I and amiRNA LRR-K II). Graph shows mean \pm std error of mean from three independent nematode infection assays that used roots from three independent transformation experiments (overall $n>18$ for each treatment). P values above each bar are color-coded for contrasts with the bar of the designated color (null hypothesis: the observed ratio between the two treatments was similar; tested by ANOVA using SAS Proc Mixed).

allow identification of transgenic tissues. Each of these ideas has ample precedent but they had not been brought together for soybean. Gmubi is a strongly expressed promoter - offering potential improvements over CaMV 35S and other promoters for use in soybean and other legumes [54,55]. Although the Arabidopsis miRNA319a has been an effective template for successful amiRNAs used in tomato, tobacco, Physcomitrella patens and other species [56,57], and was effective in the present use in soybean, it is possible in the future that improved silencing with amiRNA in soybean may be achievable by using one of the many endogenous soybean miRNAs as the template $[58,59]$. Another permutation for future investigation may be the use of highly specific promoters to drive expression of the amiRNA, to elicit silencing in a more limited set of cells, tissues or developmental stages. However, the success of amiRNA was demonstrated in the present study by the successful reduction in target mRNA abundance and by the elicitation of root development impacts in lines carrying amiRNA LRR-K I. In current work with other soybean genes, we are finding that roughly half of the amiRNAs that we construct cause detectable reduction in target mRNA abundance (unpub- 
lished), as is commonly observed in most laboratories that work with hairpin RNAs, amiRNAs and other engineered silencing methods.

The nematode demographics assay was developed as a modification of existing protocols that monitor SCN development on transgenic soybean roots generated using $A$. rhizogenes $[37,38]$. There were multiple motivations for developing the demographics approach. First and most important, we hypothesized that a census of the developmental stages achieved by the infecting SCN population mid-way through the infection life-cycle might be more sensitive than an end-stage cyst count in detecting differences in the expression SCN resistance, which is a quantitative trait. Previous reports indicate that morphological differences between nematode development on SCN-resistant and SCN-susceptible soybeans are evident relatively early - as soon as 5 days after infection $[38,53,60,61]$. Gene expression profiling work has even suggested host gene expression differences between resistant and susceptible interactions in the first 12 hours [62]. A second motivation for the demographics assay was that root segments often became less healthy in appearance after 3-4 weeks in culture. Root tips remain vigorous and continue to grow, but under our conditions, older segments such as the segments present at the time of nematode infestation start to exhibit notable decline approximately three weeks after exposure to nematodes. Data collection at an earlier time point reduces this concern. A third useful attribute of the demographics assay is that results become available two weeks earlier, compared to cyst counts at 30 days post-infection. Lastly, when first establishing the assay in our laboratory, slow-growing fungal contaminants sometimes emerged in the third or fourth week (usually introduced by application of clean but not fully sterile nematodes). Although this issue was addressed primarily by more effective nematode surfacesterilization or use of axenic nematode cultures, use of an assay that terminates two weeks after SCN application reduced contamination issues (note that more thorough surface sterilization is lethal to a high percentage of the nematodes and introduces its own potential problems). The validity of the demographics scoring approach was supported by the significant differences in SCN development we observed between known resistant and susceptible plant genotypes. Acid fuchsin staining and nematode counting do require some additional effort, however, and previously published protocols that count cyst formation after 28-35 days remain as an acceptable alternative.

In addition to reporting amiRNA use for gene silencing in soybean, a vector to facilitate this approach, and the nematode demographics assay for tests of genes that may contribute to soybean SCN resistance, we also report negative data regarding impacts of the Rhg1-locus LRR-K gene on SCN resistance. Using complementation with a full-length gene under control of its native promoter, and gene knockdown using amiRNA technology, we were unable to detect a contribution to SCN resistance by the Rhg1-locus LRR-K gene from either Peking/PI 437654 or PI 88788, the most commonly used sources of SCN resistance in U.S. soybean cultivars. An impact on root development was observed when amiRNA for the LRR-K gene were expressed in transgenic roots, and effects on root development have also been preliminarily reported by the Lightfoot research group http://hdl.handle.net/10101/ npre.2008.2726.1. It remains possible that this Rhg1-locus LRR-K gene may in some way impact SCN infection of or development on soybean roots, but no such effect was detected in our studies.

The Rhg1 locus is of extremely high economic significance to soybean cultivation in the United States, and has received attention from multiple research groups. It is notable that more than ten years after the filing of patent applications claiming SCN resistance function for the Rhg1-locus LRR-K gene, no groups have published evidence (beyond its presence as one of many candidate genes at the Rhg1 locus) for a functional contribution to SCN resistance by the Rhg1-locus LRR-K gene. We note that, simultaneous with the present study, a group led by Drs. Khalid Meksem and Melissa Mitchum has completed tests for functional contributions of the Rhg4-locus LRR-K gene to SCN resistance and, similar to our work, has not detected a contribution for this Rhg4 candidate gene (K. Meksem, personal communication). We are also aware of work led by Dr. Brian Diers (Kim et al., submitted)[], in which fine-structure genetic mapping of the Rhg1 locus has revealed chromosomal recombination events that genetically separate $r h g 1-b$ (PI 88788-source) SCN resistance function from the Rhg1-locus LRR-K gene. Hence evidence is accumulating that the $R h g 1$ locus LRR-K genes seem unlikely to be the primary source of $\mathrm{SCN}$ resistance polymorphism. A tone of caution is appropriate, however, as our present study only provides negative data on this subject. For example, gene silencing is often partial (whether mediated by VIGS, hairpin RNA-generating constucts or amiRNA), and the expression knockdown we achieved with amiRNA may have been insufficient to detectably block hypothesized SCN resistance contributions (although the other phenotypic impacts we observed with the amiRNA LRR-K I suggest that the gene expression knockdown achieved was functionally significant). As another example, the quantitative nature of the functional contribution of any given gene to $\mathrm{SCN}$ resistance may be difficult to detect in A. rhizogenes-generated soybean roots. Hence we are cautious with our conclusion, but we can state that when SCNsusceptible sources were complemented with an Rhg1locus LRR-K allele from an SCN-resistant source, or when expression of the gene in resistant plants was 
reduced by amiRNA-mediated silencing, no significant impacts on SCN resistance were detected.

\section{Conclusions}

Our findings suggest that the nematode demographics assay can expedite testing of transgenic roots for SCN resistance. amiRNAs may have widespread use in legume biology, and we have developed the vector pSM103 that drives interchangeable amiRNA constructs through a Gmubi promoter, with an intron-GFP marker for detection of transgenic roots. Studies in which expression of the Rhg1 locus LRR-kinase gene from different resistance sources was either reduced or complemented did not reveal significant impacts on SCN resistance, suggesting that one or more other genes at the Rhgl locus may be the primary determinant of differences in SCN resistance among different soybean types.

\section{Methods}

\section{Agrobacterium cultures}

A. tumefaciens GV3101 and A. rhizogenes strain Arqua1 were transformed by freeze-thaw [64] or by electroporation [65]. The cells were plated on selective media with the appropriate antibiotic and incubated at $28^{\circ} \mathrm{C}$ for about 2 days. A. rhizogenes strain Arqual was received from Dr. Jean-Michel Ane, University of Wisconsin Madison.

\section{Soybean lines}

Soybean cultivars Fayette and Ina (SCN-resistant lines), and Williams 82 and E98076 (susceptible lines) were used; E98076 is an SCN-susceptible experimental line from Dechun Wang, Michigan State University. Genotyped Ina $\times$ E98076 progeny lines were kindly provided by Dr. Brian Diers, University of Illinois at Urbana-Champaign. Those lines were inferred to be homozygous for $R h g 1_{\text {Ina }}$ or $r h g 1_{\mathrm{E} 98076}$, and for $R h g 4_{\text {Ina }}$, or $r h g 4_{\mathrm{E} 98076}$, using micro satellite markers Satt309 and Satt424 [66]; http:// soybeanbreederstoolbox.org/. DNA sequencing was used to confirm nucleotide identity between the Rhg1-locus LRR-kinase gene from cultivars Ina and Peking.

\section{Surface sterilization}

After visual screening for obvious signs of fungal or viral contamination, soybean seeds were surface-sterilized for 16-20 $\mathrm{h}$ in a desiccator jar with chlorine gas by adding, to a beaker within the jar, $3.5 \mathrm{ml} 12 \mathrm{~N} \mathrm{HCl}$ into $100 \mathrm{ml}$ household bleach (6\% sodium hypochlorite) immediately before closing the jar. At least 20 seeds per experiment were plated onto germination media (Gamborg's B5 salts (3.1 g/L), $2 \%$ sucrose, $1 \times$ Gamborg's B5 vitamins, $7 \%$ Noble agar, pH 5.8) in $100 \times 25 \mathrm{~mm}$ Petri plates. Plates were wrapped with Micropore tape (3M, St. Paul, MN) and incubated at $26^{\circ} \mathrm{C}$ in a growth chamber (18/6 light/ dark hours) for about a week. Medicago truncatula seeds (approximately 150 per batch) were scarified in concentrated sulfuric acid for $8 \mathrm{~min}$, washed 3 times in sterile water, plated on $1 \%$ deionized water agar plates, and then stratified for $24 \mathrm{~h}$ or $48 \mathrm{~h}$ at $4^{\circ} \mathrm{C}$ and germinated by incubating at room temperature overnight [67].

\section{Soybean and Medicago transformation}

Soybean cotyledons were harvested about 7 days after germination by gently twisting them off the hypocotyls. With a sterile forceps and scalpel, several shallow slices were made across the abaxial surface of the cotyledons after dipping the scalpel in $A$. rhizogenes suspension (OD600 0.7 in Luria broth). The cotyledons were then placed abaxial-side down on a co-culture medium $(0.31$ g/L Gamborg's B5 salts, 3\% sucrose, $1 \times$ Gamborg's B5 vitamins, $0.4 \mathrm{~g} / \mathrm{L}$ L-cysteine, $0.154 \mathrm{~g} / \mathrm{L}$ dithiothreitol, $0.245 \mathrm{~g} / \mathrm{L}$ sodium thiosulfate, $40 \mathrm{mg} / \mathrm{L}$ acetosyringone, $5 \%$ Noble agar, pH 5.4) in $100 \times 15 \mathrm{~mm}$ Petri plates with a piece of $70 \mathrm{~mm}$ filter paper (Whatman, Piscataway, NJ) on the surface of the agar to prevent $A$. rhizogenes from overgrowing. Plates were wrapped with parafilm and incubated in the dark at room temperature for three days. The explants were then transferred to a hairy root medium (HRM) of $4.3 \mathrm{~g} / \mathrm{L}$ MS salts (Sigma Co., St. Louis, $\mathrm{MO}$ ), $3 \%$ sucrose, $1 \times$ Gamborg's B5 vitamins (Sigma Co. St. Louis, MO), 7\% Noble agar, $0.15 \mathrm{~g} / \mathrm{L}$ cefotaxime, 0.15 $\mathrm{g} / \mathrm{L}$ carbenicillin, $\mathrm{pH} 5.6$ in $100 \times 15 \mathrm{~mm}$ Petri plates, wounded side up. Plates were wrapped with Micropore tape and incubated in the dark at room temperature until roots emerged, usually in around 3 weeks.

To generate $M$. truncatula with transgenic roots, $A$. rhizogenes Arqual carrying pSM103 with one of the two different amiRNA for the Rhg1 GmLRR-Kinase (amiRNA GmLRR-KI and GmLRR-KII), or the empty vector, were used for M. truncatula transformation [68]. Following transformation, seedlings were grown for 3 weeks. The bottom part of the plates (corresponding to the roots) was covered with aluminum foil. The plates and the $M$. trucatula composite plants were watered with sterile water every other day.

\section{Transgenic root identification and propagation}

Soybean or M. truncatula transgenic roots were detected based on GFP expression, using a fluorescence stereomicroscope (LEICA MZ FL III with GFP2 filter). Transgenic soybean root tips were cut into $2-3 \mathrm{~cm}$ segments and transferred to HRM. Roots that were expressing incomplete strips of fluorescence (chimeras) or exhibiting overall low levels of GFP fluorescence were avoided. GFPpositive as well as negative control roots were generally used within two months of the initial transformation event, after maintenance by transferring $2-3 \mathrm{~cm}$ root tips every two weeks. Independent transgenic events, gener- 
ated from different inoculation sites or different cotyledons, were maintained separately for use in RT-PCR and nematode demographic assays.

\section{Cloning of candidate Rhg 1 LRR-kinase gene}

The LRR-kinase gene Glyma18g02680.1 from the Rhg1 locus was cloned from Ina genomic DNA. Primers were designed based on BAC sequences from soybean cultivar A3244 [30], using the Primer3 tool. The Roche Expand Long $^{\text {Im }}$ (Roche Applied Science, Indianapolis, IN) kit and protocol were used with primers

Rhg1LRR-KF: TTCACCCGTGATACATGTTAATTC;

Rhg1LRR-KR: GGAACTTGGAAGTCATTATCTTGG

to amplify a $6.9 \mathrm{~kb}$ PCR product from the Rhg1 locus that includes $>2 \mathrm{~kb}$ of upstream sequence, the coding region, and $0.8 \mathrm{~kb}$ of downstream sequence, which was then cloned into the Invitrogen plasmid pCR8/GW/ TOPO according to the manufacturer's instructions. Multiple independent clones were isolated and sequenced in order to avoid clones with PCR-induced mutations. The binary vector pGWB1::erGFP7INT for full-length gene complementation experiments was constructed from pGWB1 [69] by addition of the 35S-promoter/erGFP7INT/NOS-terminator of pLMNC95 [70], taken from a pCAMBIA 1300 series vector by digestion with EcoRI and HindIII and inserted into the HindIII site of pGWB1 after blunting. The LRR-kinase genes (in $\mathrm{pCR} 8 / \mathrm{GW} / \mathrm{TOPO}$ ) from the Rhg1 locus were moved in to pGWB1::erGFP7INT using the Invitrogen Gateway ${ }^{\text {mit }}$ system (Invitrogen, Carlsbad, CA) after linearizing the pCR8/GW/TOPO-derived plasmids with XbaI. To obtain a negative control transformation vector lacking the Gateway $c c d B$ negative selectable marker, a $167 \mathrm{bp}$ segment of nonsense DNA was cloned and transferred into pGWB1::erGFP7INT.

\section{Nematode maintenance}

A Wisconsin SCN population (Hg type 7), collected by A.E.M., was maintained on the susceptible soybean cultivar Williams 82. Seeds were germinated in a wet $70 \mathrm{~mm}$ filter paper (Whatman) in a Petri plates for 4-5 days, planted in autoclaved 2:1 sand:soil mixture, inoculated with 2000-3000 eggs of $H$. glycines per container, and grown in a water bath at $28^{\circ} \mathrm{C}$ in a $28^{\circ} \mathrm{C}$ greenhouse. Cysts were collected 6 weeks after infection, and were extracted from infested pots using sieves and centrifugation. Briefly, soil from infected pots was placed in a pitcher of water and the roots were massaged to dislodge attached cyst. The soil-cyst-water slurry was passed over a $595 \mu \mathrm{m}$ - $250 \mu \mathrm{m}$ sieve tower, and the mixture from the $250 \mu \mathrm{m}$ sieve was backwashed into a $50 \mathrm{~mL}$ plastic conical tube. The tubes were centrifuged at 2000 RPM for 4 minutes then the supernatant was poured off. A $60 \%$ sucrose solution was added to the tubes, stirred, and centrifuged at
$2000 \mathrm{rpm}$ for $2 \mathrm{~min}$. Cysts in the supernatant were then collected over a $250 \mu \mathrm{m}$ sieve. Collected cysts were stored at $4^{\circ} \mathrm{C}$ in plastic bags in damp sand.

\section{Nematode demographics assay}

For nematode demographics assays, $H$. glycines eggs were collected by breaking open cysts and collecting the eggs on a sieve stack consisting of $250 \mu \mathrm{m}-74 \mu \mathrm{m}-25 \mu \mathrm{m}$ sieves (USA Standard Testing Sieve). Eggs were collected from the $25 \mu \mathrm{m}$ sieve and rinsed. Eggs were placed in a hatch chamber [71] with $3 \mathrm{mM} \mathrm{ZnCl} 2$ for hatching at room temperature in the dark for 5-6 days. Hatched J2 nematodes were surface-sterilized for $3 \mathrm{~min}$ in $0.001 \%$ mercuric chloride and washed three times with sterile distilled water [72], then suspended in $0.5 \%$ low-melting point agarose to facilitate even distribution. The number of active nematodes was counted using a hemacytometer at least one-half hour after surface-sterilization and washing, and 250-500 active J2s were inoculated onto each fresh root segments, depending on the experiment (similar numbers of active J2 were applied to all roots within an experiment). Roots (2-3 cm vigorous new root segments closest to and including root tip) with nematodes were maintained on HRM media at $28^{\circ} \mathrm{C}$ (in initial experiments including some experiments reported in Figure 1 , roots were placed on cellophane on HRM media for $24 \mathrm{hr}$. starting just before nematodes were added, and then transferred to HRM without cellophane and incubated vertically for $48 \mathrm{hr}$., then incubated horizontally until experiment was complete). Nematode infection and development within root segments was monitored by clearing and staining with acid fuchsin as in [73], typically 15 days post inoculation (dpi). The nematode demographic assay was then completed by recording the number of nematodes in each root with a morphology resembling either J2 (thin), J3 (sausage-shaped) or J4/ adult female nematodes, as noted in text and figures.

\section{Construction of amiRNA vector}

To construct the pSM103 vector for amiRNA-mediated gene silencing in legume roots (Figure 2), the 35S-promoter/erGFP7INT/NOS-terminator construct (intronGFP) from pLMNC95 [70] was mutagenized to remove $\mathrm{XbaI}$ and BamHI sites, and then cloned from pLMNC95 $(\triangle \mathrm{XbaI}$ and $\triangle \mathrm{BamHI}$ ) into pCAMBIA 1300 after PCRmediated addition of restrictions sites using the primers:

Plmnc95_Kpn1F: CCAGGTACCCAGGTCCCCAGATTAGCC;

Plmnc95EcoR1_R: GCCAGTGAATTCCCGATCTA.

The amiRNA constructs from pRS300 derivatives (see below) were added to pCAMBIA 1300::35SPerGFP7INT-NOS using BamHI/PstI sites. The soybean polyubiquitin (gb|EU310508.1|) promoter (GmUbi) 
[54,55] was amplified from Fayette genomic DNA with added HindIII and PstI sites using the primers:

Ubi1_HindIII_Fa: CCAAAGCTTGGGCCCAATATAACAACGAC;

Ubi_PstI_Ra: CCACTGCAGCTGTCGAGTCAACAATCA.

The Gmubi product was cloned into pCR2.1 TOPO and then in pCAMBIA 1300::35SP-erGFP7INTNOS::miR319a using HindIII/PstI sites.

\section{Transient Expression Assay}

The plasmids pGWB1::erGFP7INT, pSM101 and pSM103 were initially tested for GFP function by agroinfiltration of A. tumefaciens GV3101 into Nicotiana benthamiana leaves, along with GV3101 without binary plasmid as a negative control. A. tumefaciens GV3101 strains carrying pGWB1::erGFP7INT, pSM101 and pSM103 were grown overnight at $28^{\circ} \mathrm{C}$ in $5 \mathrm{ml} \mathrm{LB}$ medium with $2.5 \mu \mathrm{g} / \mathrm{ml}$ of rifampicin and $50 \mu \mathrm{g} / \mathrm{ml}$ of kanamycin (the negative control A. tumefaciens GV3101 without binary vector was grown only with rifampicin). A. tumefaciens cells were harvested by centrifugation and resuspended to $\mathrm{OD}_{600} 0.4$ in MMA induction buffer $(5 \mathrm{~g}$ MS salts, $20 \mathrm{~g}$ sucrose, $1.95 \mathrm{~g}$ MES per liter, $200 \mu \mathrm{M}$ acetosyringone, $\mathrm{pH}$ to 5.6 with $1 \mathrm{M} \mathrm{NaOH}$. Bacterial suspensions were then incubated at room temperature for $1-3 \mathrm{hr}$ prior to infiltration through the abaxial surface into the leaf, using a syringe with no needle. GFP fluorescence was investigated 3 days after infiltration in excised leaf sections that included the infiltrated zone and $1-3 \mathrm{~cm}$ of surrounding non-infiltrated tissue, using an Olympus BX-60 upright Fluorescence Microscope and MF filter.

\section{Sequencing and amiRNA design}

EST TC204550 UP|Q8L3Y5 (Q8L3Y5) (Glycine max EST GmGI-12.0; wmd2 database http:// wmd2.weigelworld.org/cgi-bin/mirnatools.pl) corresponding to the Glyma18g02680.1 putative LRR-kinase gene from the Rhg1 locus was used to design PCR primers for isolation of the Rhg1 locus receptor-like kinaseencoding allele from the resistant source Fayette, which carries the $R h g 1$ resistance allele $r h g 1-b$ from PI 88788. The primers RTPCR_TC204550F CAA CTT CAA GGC CTC AGG AA; RTPCR_TC204550R GCT ACC CAA AGA AGC AGG AA, amplified a PCR product of $450 \mathrm{bp}$. The DNA sequences of PCR products were determined by the dideoxy chain-termination method using ABI big dye cycle sequencing kit (3.1) and the ABI 377 automated sequencing service at the University of Wisconsin - Madison Biotechnology Center. Blast analysis of the Fayette version of TC204550 (the EST for this gene in earlier WMD versions) was conducted in March 2008 using the Phytozome database http://www.phytozome.net/soybean. For amiRNA design, the sequence of this Fayette
LRR-kinase gene was submitted to http:// wmd2.weigelworld.org. The wmd2 tool identified a total of 85 candidate amiRNA sequences to potentially silence the Rhg1 locus LRR-kinase gene, with the first 31 candidates classified by wmd2 as having excellent (most promising) properties (data not shown). The two amiRNA target sequences selected for primer design to modify pRS300 for silencing of the Rhg1 locus LRR-kinase gene were identical to Fayette chromosome 18 sequence as well as the paralogous chromosome 11 sequence from the Williams 82 genome: amiRNA GmLRR-KI: TAAGACTATAAGGGATTGCTG; and amiRNA LRR-KII: TAAGACTATAAGGGATTGCTC. The Arabidopsis miR319a sequence from pRS300 was used as a template to create three PCR products $(\mathrm{a}, \mathrm{b}, \mathrm{c})$ with soybean target transcript specificity. These products were used as template for a fourth PCR using overlapping primers to create gene specific amiRNA [51]. The final PCR product (containing target transcript sequence) was cloned into pSM103 using BamHI-PstI restriction sites, replacing the miR319a sequence. Presence of the desired amiRNA was confirmed by DNA sequencing.

\section{DNA and RNA extraction and RT-PCR}

Soybean genomic DNA was extracted from young leaves using a CTAB method previously described [74]. Total RNA was extracted from independent transgenic hairy roots (about $3 \mathrm{~cm}$ long) that had been frozen in liquid nitrogen and stored at $-80^{\circ} \mathrm{C}$ until use. Total RNA was isolated using Qiagen RNeasy Mini Kit according to the manufacturer's instructions, and treated with RNase-free DNase I (Qiagen, Valencia, CA, U.S.A.). First-strand cDNA was synthesized from $250 \mathrm{ng}$ of DNase-treated RNA using SuperScript III Reverse Transcriptase. The RNA concentration was determined using the NanoDrop-1000 Spectophotometer. Semi-quantitative RTPCR was performed using $25 \mathrm{ng}$ of cDNA. Primers designed from the Fayette Rhg1 locus LRR-Kinase target, RTPCR_TC204550F CAACTTCAAGGCCTCAGGAA (forward) and RTPCR_TC204550R GCTACCCAAAGAAGCAGGAA (reverse), were used to amplify a $450 \mathrm{bp}$ product. As a control for equivalent starting pools of cDNA, the primers Actin forward GTTCTCTCCTTGTATGCAAGTG and Actin reverse CCAGACTCATCATATTCACCTTTAG were used to amplify a $700 \mathrm{bp}$ segment of soybean actin gene cDNA (emb|V00450.1|) The RT-PCR was performed in triplicate at $55^{\circ} \mathrm{C}$, testing three different numbers of cycles (30-35-40) to confirm non-saturation of amplification. PCR products were visualized by ethidium bromide staining after separation on $1.5 \%$ agarose gels and band intensity was quantified using the Kodak 1D Image Analysis Software v3.6. 


\section{Statistical analysis}

Data were analyzed by ANOVA using Minitab (v.14) with the General Linear Model and Tukey Simultaneous Test; nematode demographics data for the amiRNA experiments were analyzed using a mixed model (Mixed Procedure; SAS, vers. 9.1).

\section{Authors' contributions}

SM, ALH and DC planned, conducted and analyzed most of the experiments and were centrally involved in writing the manuscript. BWD developed soybean germplasm and provided significant ideas and critical review of the manuscript. AEM contributed nematode populations, methodological suggestions and biological insights. AFB conceived the overall project, analyzed results and planned experiments, and was a primary author of the manuscript. All authors read and approved the final manuscript.

\section{Acknowledgements}

This project was supported by grants to A.B. from the Wisconsin Agricultural Research Station, the Wisconsin Soybean Marketing Board and the United Soybean Board. We thank Jean-Michel Ane and Muthusubramanian Venkatashwaran for the Arqual strain, helpful discussions and assistance with Medicago experiments, Michelle Graham for early help in identifying regions of duplication between the Gm18 Rhg 1 locus and Gm11, and Melissa Mitchum for advice about SCN testing with A. rhizogenes-generated roots and for critical reading of the manuscript.

\section{Author Details}

'Department of Plant Pathology, University of Wisconsin - Madison, Madison, WI 53706 USA and ${ }^{2}$ Department of Crop Sciences, University of Illinois at Urbana-Champaign, Urbana, IL 61801 USA

Received: 19 March 2010 Accepted: 9 June 2010

Published: 9 June 2010

\section{References}

1. Wrather JA, Koenning SR: Estimates of disease effects on soybean yields in the United States 2003 to 2005. J Nematol 2006, 38(2):173-180.

2. Niblack TL, Lambert KN, Tylka GL: A model plant pathogen from the kingdom animalia: Heterodera glycines, the soybean cyst nematode. Annual Review of Phytopathology 2006, 44:283-303.

3. Ithal N, Recknor J, Nettleton D, Hearne L, Maier T, Baum TJ, Mitchum MG: Parallel genome-wide expression profiling of host and pathogen during soybean cyst nematode infection of soybean. Molecular PlantMicrobe Interactions 2007, 20(3):293-305.

4. Lauritis JA, Rebois RV, Graney LS: Development of Heterodera-Glycines Ichinohe on Soybean, Glycine-Max (L) Merr, under Gnotobiotic Conditions. Journal of Nematology 1983, 15(2):272-281.

5. Davis EL, Hussey RS, Mitchum MG, Baum TJ: Parasitism proteins in nematode-plant interactions. Current Opinion in Plant Biology 2008, 11(4):360-366

6. Halbrendt JM, Lewis SA, Shipe ER: A Technique for Evaluating Heterodera glycines Development in Susceptible and Resistant Soybean. J Nematol 1992, 24(1):84-91.

7. Colgrove AL, Niblack TL: Correlation of Female Indices From Virulence Assays on Inbred Lines and Field Populations of Heterodera glycines. $J$ Nematol 2008, 40(1):39-45.

8. Schmitt DP, Shannon G: Differentiating Soybean Responses to Heterodera Glycines Races. Crop Sci 1992, 32(1):275-277.

9. Brucker E, Carlson S, Wright E, Niblack T, Diers B: Rhg1 alleles from soybean PI 437654 and PI 88788 respond differentially to isolates of Heterodera glycines in the greenhouse. Theor Appl Genet 2005, 111(1):44-49.

10. Concibido VC, Diers BW, Arelli PR: A decade of QTL mapping for cyst nematode resistance in soybean. Crop Sci 2004, 44:1121-1131.

11. Concibido VC, Lange DA, Denny RL, Orf JH, Young ND: Genome mapping of soybean cyst nematode resistance genes in Peking, PI 90763, and PI 88788 using DNA markers. Crop Sci 1997, 37:258-264.

12. Caldwell BE, Brim CA, Ross JP: Inheritance of Resistance of Soybeans to the Cyst Nematode, Heterodera Glycines. Agron J 1960, 52:635-636.
13. Shier M: Soybean varieties with soybean cyst nematode resistance. 2008 [https://netfiles.uiuc.edu/tjw/www/cover.htm]. (verified 1 Feb 2010)

14. Webb DM, Baltazar BM, Rao-Arelli AP, Schupp J, Clayton K, Keim P, Beavis WD: Genetic mapping of soybean cyst nematode race-3 resistance loci in the soybean PI 437654. Theor Appl Genet 1995, 91:574-558.

15. Cregan PB, Jarvik T, Bush AL, Shoemaker RC, Lark KG, Kahler AL, Kaya N, VanToai TT, Lohnes DG, Chung L, Specht JE: An integrated genetic linkage map of the soybean genome. Crop Science 1999, 39:1464-1490.

16. Cregan PB, Mudge J, Fickus EW, Danesh D, Denny R, Young ND: Two simple sequence repeat markers to select for soybean cyst nematode resistance conditioned by the rhg 1 locus. Theoretical and Applied Genetics 1999, 99:811-818.

17. Schmutz J, Cannon SB, Schlueter J, Ma J, Mitros T, Nelson W, Hyten DL, Song Q, Thelen JJ, Cheng J, et al: Genome sequence of the palaeopolyploid soybean. Nature 2010, 463(7278):178-183.

18. Lightfoot DA, Meksem K: Isolated polynucleotides and polypeptides relating to loci underlying resistance to soybean cyst nematode and soybean sudden death syndrome and methods employing same. U.S. Patent Application No. 200201443102001

19. Ruben E, Jamai A, Afzal J, Njiti VN, Triwitayakorn K, labal MJ, Yaegashi S, Bashir R, Kazi S, Arelli P, et al:. Genomic analysis of the rhg 1 locus: candidate genes that underlie soybean resistance to the cyst nematode. Mol Genet Genomics 2006, 276(6):503-516.

20. Keim P, Diers BW, Olson TC, Shoemaker RC: RFLP mapping in soybean: Association between marker loci and variation in quantitative traits. Genetics 1990, 126:735-742.

21. Riggs RD, Schmitt DP: Complete characterization of the race scheme for Heterodera glycines. J Nematol 1988, 20:392-395.

22. Wu X, Blake S, Sleper DA, Shannon JG, Cregan P, Nguyen HT: QTL, additive and epistatic effects for $\mathrm{SCN}$ resistance in $\mathrm{PI}$ 437654. Theor Appl Genet 2009, 118(6):1093-1105.

23. Winter SM, Shelp BJ, Anderson TR, Welacky TW, Rajcan I: QTL associated with horizontal resistance to soybean cyst nematode in Glycine soja PI464925B. Theor Appl Genet 2007, 114(3):461-472

24. Guo B, Sleper DA, Arelli PR, Shannon JG, Nguyen HT: Identification of QTLs associated with resistance to soybean cyst nematode races 2, 3 and 5 in soybean PI 90763. Theor Appl Genet 2005, 111(5):965-971.

25. Qiu BX, Arelli PR, Sleper DA: RFLP markers associated with soybean cyst nematode resistance and seed composition in a 'Peking' $\times$ 'Essex' population. Theoretical and Applied Genetics 1999, 98:356-364.

26. Afzal AJ, Natarajan A, Saini N, labal MJ, Geisler M, El Shemy HA, Mungur R, Willmitzer L, Lightfoot DA: The Nematode Resistance Allele at the rhg1 Locus Alters the Proteome and Primary Metabolism of Soybean Roots. Plant Physiol 2009, 151(3):1264-1280.

27. Mahalingam R, korupska HT: Cytological expression of early response to infection by Heterodera glycines Ichinohe in resistant PI 437654 soybean. Genome 1996, 39:986-998.

28. Brucker E, Carlson S, Wright E, Niblack TL, Diers BW: Rhg1 alleles from soybean PI 437654 and $\mathrm{PI} 88788$ respond differentially to isolates of Heterodera glycines in the greenhouse. Theor Appl Genet 2005, 111:44-49.

29. Klink VP, Hosseini P, MacDonald MH, Alkharouf NW, Matthews BF: Population-specific gene expression in the plant pathogenic nematode Heterodera glycines exists prior to infection and during the onset of a resistant or susceptible reaction in the roots of the Glycine max genotype Peking. Bmc Genomics 2009, 10:111.

30. Hauge BM, Wang ML, Parsons JD, Parnell LD: Nucleic acid molecules and other molecules associated with soybean cyst nematode resistance. U.S. Patent Application No. 20300054912001

31. Hauge BM, Wang ML, Parsons JD, Parnell LD: Nucleic acid molecules and other molecules associated with soybean cyst nematode resistance. 2006. U.S. Patent No. 7,154,021

32. Mrosk C, Forner S, Hause G, Küster H, Kopka J, Hause B: Composite Medicago truncatula plants harbouring Agrobacterium rhizogenestransformed roots reveal normal mycorrhization by Glomus intraradices. J Exp Bot 2009, 60(13):3797-3807.

33. Boisson-Dernier ACM, Garcia F, Bécard G, Rosenberg C, Barker DG Agrobacterium rhizogenes-transformed roots of Medicago truncatula for the study of nitrogen-fixing and endomycorrhizal symbiotic associations. Mol Plant Microbe Interact 2001, 14(6):695-700. 
34. Mazarei M, Miao B, Paiva NL: Cotransformed hairy roots of soybean: a rapid system for in vivo plant promoter analysis. Phytopathology 1996 86(S93):

35. Kereszt A, Li D, Indrasumunar A, Nguyen CD, Nontachaiyapoom S, Kinkema M, Gresshoff PM: Agrobacterium rhizogenes-mediated transformation of soybean to study root biology. Nat Protoc 2007 2(4):948-952.

36. Olhoft PM, Bernal LM, Grist LB, Hill DS, Mankin SL, Shen YW, Kalogerakis M, Wiley $\mathrm{H}$, Toren $\mathrm{E}$, Song HS, et al:: A novel Agrobacterium rhizogenesmediated transformation method of soybean [Glycine max (L.) Merrill] using primary-node explants from seedlings. In Vitro Cellular and Developmental Biology - Plant 2007, 43(6):536-549.

37. Cho HJ, Farrand SK, Noel GR, Widholm JM: High-efficiency induction of soybean hairy roots and propagation of the soybean cyst nematode. Planta 2000, 210(2):195-204.

38. Narayanan R, Atz R, Denny R, Young N, Somers D: Expression of soybean cyst nematode resistance in transgenic hairy roots of soybean. Crop Sci 1999, 39:1680-1686.

39. Small I: RNAi for revealing and engineering plant gene function. Curr Opinion Biotechnol 2004, 18:148-153.

40. Baulcombe D: RNA silencing in plants. Nature 2004, 431:356-363.

41. Baulcombe D: RNA silencing. Trends Biochem Sc 2005, 30:290-293.

42. Wesley SV, Helliwell CA, Smith NA, Wang M, Rouse DT, Liu Q, Gooding PS, Singh SP, Abbott D, Stoutjesdijk PA, et al:: Construct design for efficient, effective and high-throughput gene silencing in plants. Plant J 2001, 27(6):581-590.

43. Wasson AP, Pellerone Fl, Mathesius U: Silencing the Flavonoid Pathway in Medicago truncatula Inhibits Root Nodule Formation and Prevents Auxin Transport Regulation by Rhizobia. The Plant Cell 2006, 18:1617-1629

44. Ivashuta S, Liu J, Liu J, Lohar DP, Haridas S, Bucciarelli B, VandenBosch KA Vance CP, Harrison MJ, Gantt JS: RNA interference identifies a calciumdependent protein kinase involved in Medicago truncatula root development. Plant Cell 2005, 17(11):2911-2921.

45. Constantin GDGM, Johansen IE, Stougaard J, Lund OS: Virus-induced gene silencing (VIGS) as a reverse genetic tool to study development of symbiotic root nodules. Mol Plant Microbe Interact 2008, 21(6):720-727.

46. Nagamatsu A, Masuta C, Matsuura H, Kitamura K, Abe J, Kanazawa A Down-regulation of flavonoid 3'-hydroxylase gene expression by virusinduced gene silencing in soybean reveals the presence of a threshold mRNA level associated with pigmentation in pubescence. J Plant Physiol 2009, 166(1):32-39.

47. Nagamatsu A, Masuta C, Senda M, Matsuura H, Kasai A, Hong JS, Kitamura K, Abe J, Kanazawa A: Functional analysis of soybean genes involved in flavonoid biosynthesis by virus-induced gene silencing. Plant Biotechnol J 2007, 5(6):778-790.

48. Subramanian S, Graham MY, Yu O, Graham TL: RNA interference of soybean isoflavone synthase genes leads to silencing in tissues distal to the transformation site and to enhanced susceptibility to Phytophthora sojae. Plant Physiol 2005, 137(4):1345-1353.

49. Graham TL, Graham MY, Subramanian S, Yu O: RNAi silencing of genes for elicitation or biosynthesis of 5-deoxyisoflavonoids suppresses racespecific resistance and hypersensitive cell death in Pytophthora sojae infected tissues. Plant Physiology 2007, 144(2):728-740.

50. Schwab R, Palatnik JF, Riester M, Schommer C, Schmid M, Weigel D: Specific effects of microRNAs on the plant transcriptome. Dev Cell 2005, 4:517-527.

51. Schwab R, Ossowski S, Riester M, Warthmann N, Weigel D: Highly specific gene silencing by artificial microRNAs in Arabidopsis. Plant Cell 2006, 18(5):1121-1133.

52. Warthmann $\mathrm{N}$, Chen $\mathrm{H}$, Ossowski S, Weigel D, Herve P: Highly specific gene silencing by artificial miRNAs in rice. PLoS One 2008, 3(3):e1829.

53. Halbrendt J, Lewis S, Shipe E: A technique for evaluating Heterodera glycines development in susceptible and resistant soybean. Journal of Nematology 1992, 24:84-91.

54. Hernandez-Garcia CM, Martinelli AP, Bouchard RA, Finer JJ: A soybean (Glycine max) polyubiquitin promoter gives strong constitutive expression in transgenic soybean. Plant Cell Reports 2009, 28(5):837-849.

55. Chiera JM, Bouchard RA, Dorsey SL, Park E, Buenrostro-Nava MT, Ling PP, Finer JJ: Isolation of two highly active soybean (Glycine max (L.) Merr.) promoters and their characterization using a new automated image collection and analysis system. Plant Cell Reports 2007, 26(9):1501-1509.

56. Khraiwesh B, Ossowski S, Weigel D, Reski R, Frank W: Specific gene silencing by artificial MicroRNAs in Physcomitrella patens: an alternative to targeted gene knockouts. Plant Physiol 2008, 148(2):684-693.

57. Alvarez JP, Pekker I, Goldshmidt A, Blum E, Amsellem Z, Eshed Y: Endogenous and synthetic microRNAs stimulate simultaneous, efficient, and localized regulation of multiple targets in diverse species. Plant Cell 2006, 18(5):1134-1151.

58. Zhang B, Pan X, Stellwag EJ: Identification of soybean microRNAs and their targets. Planta 2008, 229(1):161-182.

59. Zhang Z, Yu J, Li D, Zhang Z, Liu F, Zhou X, Wang T, Ling Y, Su Z: PMRD: plant microRNA database. Nucleic Acids Res 2010:D806-813.

60. Endo BY: Histological responses of resistant and susceptible soybean varieties and backgross progeny to entry and development of Heterodera glycines. Phytopathology 1965, 55:375-381.

61. Colgrove AL, Niblack TL: Correlation of Female Indices From Virulence Assays on Inbred Lines and Field Populations of Heterodera glycines. J Nematol 2008, 40(1):39-45.

62. Klink VP, Overall CC, Alkharouf NW, MacDonald MH, Matthews BF: A timecourse comparative microarray analysis of an incompatible and compatible response by Glycine max (soybean) to Heterodera glycines (soybean cyst nematode) infection. Planta 2007, 226(6):1423-1447.

63. Kim M, Hyten DL, Bent AF, Diers BW: Fine mapping of the SCN resistance locus rhg1-b from PI 88788. Plant Genome 2010 in press.

64. Höfgen R, Willmitzer L: Storage of competent cells for Agrobacterium transformation. Nucleic Acids Res 1988, 16(20):9877.

65. Wise AA, Liu Z, Binns AN: Three methods for the introduction of foreign DNA into Agrobacterium. Methods Mol Biol 2006, 343:43-53.

66. Song QJ, Marek LF, Shoemaker RC, Lark KG, Concibido VC, Delannay X, Specht JE, Cregan PB: A new integrated genetic linkage map of the soybean. Theoretical and Applied Genetics 2004, 109(1):122-128.

67. Peiter E, Sun J, Heckmann A, Venkateshwaran M, Riely B, Otegui M Edwards A, Freshour G, Hahn M, Cook D, et al:: The Medicago truncatula DMI1 protein modulates cytosolic calcium signaling. Plant Physiology 2007, 145(1):192-203

68. Boisson-Dernier A, Chabaud M, Garcia F, Bécard G, Rosenberg C, Barker DG: Agrobacterium rhizogenes-transformed roots of Medicago truncatula for the study of nitrogen-fixing and endomycorrhizal symbiotic associations. Molecular Plant-Microbe Interactions 2001 14:695-700

69. Nakagawa T, Kurose T, Hino T, Tanaka K, Kawamukai M, Niwa Y, Toyooka K, Matsuoka K, Jinbo T, Kimura T: Development of series of gateway binary vectors, pGWBs, for realizing efficient construction of fusion genes for plant transformation. Journal of bioscience and bioengineering 2007, 104(1):34-41.

70. Mankin SL, Thompson WF: New green fluorescent protein genes for plant transformation: Intron-containing, ER-localized, and solublemodified. Plant Molecular Biology Reporter 2001, 19(1):13-26.

71. Schroeder NE, MacGuidwin AE: Uptake of FITC by Heterodera glycines is inhibited by stomal occlusion and quiescence. Journal of Nematology 2006, 38(2):291-292.

72. Sindhu AS, Maier TR, Mitchum MG, Hussey RS, Davis EL, Baum TJ: Effective and specific in planta RNAi in cyst nematodes: expression interference of four parasitism genes reduces parasitic success. Journal of Experimental Botany 2009, 60(1):315-324

73. Byrd DWJ, Kirkpatrick T, Barker KR: An improved technique for clearing and staining plant tissues for detection of nematodes. J Nematol 1983, 15:142-143.

74. Murray MGTW: Rapid isolation of high molecular weight plant DNA. Nucleic Acids Res 1980, 8:4321-4325.

doi: 10.1186/1471-2229-10-104

Cite this article as: Melito et al., A nematode demographics assay in transgenic roots reveals no significant impacts of the Rhg1 locus LRR-Kinase on soybean cyst nematode resistance BMC Plant Biology 2010, 10:104 